\title{
El restabliment de la Companyia de Jesús a València
}

\author{
The reestablishment of the Society of Jesus in València
}

\author{
Francesc-Joan Monjo i Dalmau \\ tirant_cat@hotmail.com \\ Universitat d'Alacant
}

\begin{abstract}
Resum: L'expulsió de la Companyia de Jesús, decretada per Carles III el 1767, obrí un llarg període de foscor per als jesuïtes hispànics. Tanmateix, el cop de gràcia a l'orde vindria de la mà del papa Climent XIV, que, pressionat per la monarquia espanyola -l'ambaixador del rei hispànic a Roma Moñino recorregué a la coacció i al suborn d'afins al pontífex-, declarà extingida la Companyia el 21 de juliol del 1773. Els jesuites suprimits van conrear la propaganda durant més de quaranta anys per tal de revertir la situació. Finalment, el 1814 el papa Pius VII restablí l'orde jesuïta a tot el món mitjançant la butlla Sollicitudo omnium ecclesiarum, i els regulars ignasians van obtenir, un any després, el desitjat permís de Ferran VII per tornar als territoris hispànics. El 18 de juliol del 1816 els jesuites prenien possessió de la Casa Professa, ara convertida en col legi.
\end{abstract}

Paraules clau: Jesuïtes, restauració, Pius VII, Ferran VII, València

\begin{abstract}
The expulsion of the Society of Jesus, decreed by Charles III of Spain in 1767, initiated a long period of darkness for the Hispanic Jesuits. Although the coup de grace to the order would come by the hands of Pope Clement XIV, who was pressured by the Spanish monarchy (the ambassador of the Hispanic king in Rome Moñino resorted to the coercion and subornation of those who were related to the pontiff), declared the Society extinguished on July 21, 1773. The suppressed Jesuits produced propaganda for more than forty years to reverse the situation. Finally, in 1814 Pope Pius VII restored the Jesuit Order around the world through the Bull Sollicitudo omnium ecclesiarum, and one year later the regular Ignatians obtained the desired permission from Ferdinand VII to return to the Hispanic territories. On July 18, 1816, the Jesuits took possession of Casa Professa, now converted into a school.
\end{abstract}

Keywords: Jesuits, restoration, Pius VII, Ferdinand VII, València. 


\section{Introducció}

Des de la fundació de l'orde de sant Ignasi, els jesuïtes van desplegar una intensa activitat intel lectual (literària, científica, teològica i filosòfica), docent, pastoral i missionera, i aconseguiren gran celebritat en el món catòlic. Amb el temps, però, es van multiplicar els seus enemics. I és que si els regulars de la Companyia de Jesús havien sabut guanyar-se importants simpaties, també van despertar odis i recels en altres ordes religiosos, en alguns membres de la jerarquia eclesiàstica i en els ministres reformadors i regalistes del període de la Il lustració. Aquests els acusaven d'aspirar a influir en els governs, de controlar l'educació de les elits, de promoure avalots, d'intentar manipular les consciències dels fidels, de mantenir teories subversives $\mathrm{i}$ immorals, d'avidesa pels diners, etc.

El quart vot d'especial obediència al papa que pronunciaven els pares professos va ser interpretat pels regalistes com una submissió excessiva dels regulars de la Companyia a les directrius dels pontífex, per damunt, fins i tot, dels interessos del rei. Per això, l'orde jesuïta estigué en el punt de mira dels ministres del rei Borbó, els quals consideraven els regulars ignasians individus molestos i, fins i tot, perillosos -els veien enemics del poder reial i un perill per a la salvaguarda de l'imperi-, que calia foragitar dels territoris hispànics i eradicar de l'orbe catòlic.

La solució final de Carles III, en un acte de regalisme extrem, va ser fer-los fora dels seus dominis (dels regnes hispànics peninsulars i dels territoris d'ultramar: Amèrica i Filipines). Per la via urgent i per sorpresa, els regulars de la Companyia passarien a ser proscrits, reus de lesa majestat, mereixedors de la «pena del extrañamiento». I els béns de l'orde, confiscats per la corona, serien subhastats, venuts o donats. El detonant van ser els motins contra Esquillace del 1766 -atribuits als jesuïtes sense cap prova fefaent-i es va voler seguir l'exemple del marqués de Pombal, que ja havia bandejat els ignasians dels dominis del rei de Portugal el 1759. El resultat: una mesura pròpia d'un poder absolutista, sense informar dels càrrecs als reus, sense audiència i sense donar-los la més mínima ocasió per defensar-se.

D'acord amb les minucioses i secretes ordres dissenyades pel comte d'Aranda, la matinada del 3 d'abril del 1767 els jutges comissionats, revestits de poders extraordinaris i acompanyats per soldats amb baioneta calada, entraren, sobtadament, a les cases i als col legis jesuïtes per llegir-los el reial decret que els condemnava a l'exili, primer a Còrsega -els valencians van ser desembarcats en el municipi de Bunifazziu, on van haver de viure en unes condicions summament penoses- i, després, als Estats Pontificis -els valencians van ser confinats a la ciutat de Ferrara. Van ser 190 els jesuites que pertanyien a col legis valencians (Oriola, Alacant, Gandia, Ontinyent, Torrent, València i Sogorb) els que van viure en carn pròpia l'amarg i llarg exili (Monjo i Dalmau 2016).

Les corts borbòniques, no prou satisfetes amb l'expulsió, demanarien al recentment coronat papa Climent XIV que acabara, d'una vegada per sempre, amb l'orde jesuïta -Moñino, ambaixador de Carles III a Roma, va ser una peça clau en aquest afer. El 21 de juliol del 1773 el pontífex aprovava el breu Dominus ac Redemptor, pel qual la Companyia de Jesús quedava extingida: el papa considerà els jesuïtes pertorbadors de la pau de l'Església (O’Malley 2017: 115-119). 
Des d'aquest mateix moment deixaven de ser jesuïtes i havien d'abandonar la sotana -signe extern de la seua identitat- i fer-se'n una altra com la que portaven els clergues italians. Els religiosos de l'extingida Companyia van haver d'acceptar un desenllaç que no pensaven mai que arribaria. Així, quedaren mancats d'esperança i auguraven un futur ple de dificultats. Suprimits, empobrits -no podien viure únicament de la pensió- i sense possibilitats de tornar al seu país, els ara exjesuïtes intentaren refer les seues vides integrant-se en la societat italiana. Mentre els uns es dedicaren a la docència o a l'estudi publicant treballs -molts d'ells es convertiren en apologetes o participaren en polèmiques de caire intel lectual a nivell europeu-, d'altres, els germans, buscaren guanyar-se la vida en les activitats manuals, feines precàries i quasi sempre molt mal remunerades.

\section{La restauració de l'orde}

Malgrat la supressió, la Companyia de Jesús no va morir del tot, ja que va sobreviure a la Rússia Blanca, sota la protecció de la tsarina ortodoxa Caterina II, i també a la Prússia del luterà Frederic II, que no permeteren, de moment, publicar el breu d'extinció de l'orde. Allà, l'Institut ignasià perdurà poc més de temps seguint amb els seus estudis i amb la reorganització del més selecte de la intel lectualitat de l'orde. Així, la Companyia fou suprimida però no extingida. I com si de la mitològica Au Fènix es tractara, la qual es crema en viu i renaix de les seues pròpies cendres, el diumenge 7 d'agost del 1814 -quaranta-un anys després de la seua supressió- els supervivents exjesuïtes van rebre la butlla de Pius VII Sollicitudo omnium ecclesiarum que restablia la Companyia de Jesús a tot el món (Revuelta 2013). Aquesta, signada pel papa a Santa Maria Maggiore, va ser llegida per monsenyor Belisario Cristaldi en el temple romà d'Il Gesù (església mare de l'orde jesuïta) i davant la presència del pontífex, quedant derogat, així, el breu d'extinció de Climent XIV (Nonell 1893: vol. III 311-313). Aquest esdeveniment va suposar la reaparició, el ressorgiment, el renaixement, la resurrecció de l'orde de sant Ignasi. El P. Luengo, de la província jesuïta de Castella, que no va perdre detall del solemne acte, el descriu de la manera següent:

\footnotetext{
A las ocho de la mañana llegó el Santo Padre a la puerta de la iglesia del Jesús, bellísimamente colgada e iluminada a maravilla, y en ella fue recibido por el colegio de los cardenales, que en toda gala, según se les había advertido, habían prevenido el arribo de su Santidad. El Pontífice, después de una breve oración al sacramento, se fue a celebrar la santa misa en el magnificentísimo altar del patriarca San Ignacio, en el que reposa su santo cuerpo, y habiendo dicho otra allí mismo un monseñor o prelado mientras su Santidad daba gracias, se fue pompamente, abriendo a viva fuerza los soldados camino por la iglesia llena de gente, a la sacristía de la capilla de los nobles, y habiendo tomado en un momento algún desayuno, salió al instante y se asentó en su trono para hacerse a su presencia la lectura de la bula de restablecimiento de la Compañía. En el centro de la capilla, que no es grande y por eso no se dio entrada a ningún otro que no tuviese parte en la función, estaban en sus bancos dieciocho cardenales, y por sus indisposiciones no vinieron y enviaron sus excusas otros cuatro, y son Carrafa, Breschi, Pignatelli y Caraciolo. A espaldas de los cardenales, en dos filas de bancos por cada lado, estábamos
} 
generalmente todos los jesuitas que estamos en Roma, unos pocos portugueses, en mayor número italianos y la mayor parte españoles, y entre todos llegaríamos a ciento cincuenta (Fernández Arrillaga 2014: 80).

Assegut Pius VII en el seu tron, monsenyor Cristaldi va rebre de la mà del sant pare la butlla, la va llegir cerimoniosament i la tornà a lliurar al pontífex. El papa va cridar el pare Luigi Panizzoni, superior provincial dels jesuïtes italians, i diposità a les seues mans el document pontifici que acreditava la restitució de la Companyia de Jesús. Tot seguit, li besà els peus i es retirà. Aquest gest, executat en senyal de reverència i d'acatament, va ser repetit per tots els membres de ple dret de l'Institut ignasià. Havent finalitzat el cerimonial, el cardenal camarlenc Bartolomeo Pacca llegí les condicions de la reposició de la Companyia: s’instal larien a la casa central de Roma el P. Panizzoni, com a provincial o vicari general; el P. Simoncini, com a viceprepòsit; el valencià, natural de la vila de Planes, Francesc Català, com a ministre, i el jesuïta de la província d'Aragó Alejandro Battier com a procurador.

Des que el papa Climent XIV va suprimir la Companyia de Jesús el 1773, els exignasians no podien vestir amb la seua sotana. En aquest acte a l'església del Gesù, els ara ja jesuïtes, amb tota legitimitat, van assistir feliços i abillats amb la vestidura talar de la Companyia -que lluïen amb orgull-, i els regulars proscrits amb el gran desig de tornar a la seua pàtria.

L'Institut de la Companyia renaixia però en un terreny insegur, tant en les monarquies absolutes com en els règims liberals. En la monarquia espanyola, de valors tradicionals i religiosos, arribaven a la cort peticions de diverses ciutats, personalitats i institucions que demanaven que tornaren els jesuïtes restaurats. Aquestes demandes van ser sotmeses a estudi pel Consell de Castella, i el fiscal Francisco Gutiérrez de la Huerta, en el seu dictamen, presentat el 1815, parlava de la conveniència del restabliment general de la Companyia. A més a més, deia el fiscal que les imputacions que es van fer per a justificar l'expulsió i posterior extinció de l'orde ignasià no van ser ni justes ni imparcials (Gutiérrez de la Huerta 1845).

Des de la publicació de la butlla de restauració dels jesuïtes, el rei hispànic Ferran VII va trigar quasi un any a donar el primer permís limitat a les ciutats que van demanar-ne la presència (29-05-1815), i l'any següent, amb el dictamen del fiscal i del Consell Reial a les mans, decretà el restabliment total i sense limitacions de l'orde religiós (3-05-1816). Com assenyala Revuelta González, aquesta reconstitució encaixava en l'ambient de restauració política i religiosa que s'implantà a Europa després de la crisi de la Revolució Francesa i de l'Imperi Napoleònic. Però en els regnes hispànics l'ambient restaurador va adquirir una duresa especial, ja que el monarca va unir a la restauració del tron absolut una forta repressió contra els liberals. El rei va desfer el que aquests havien fet, i pel que fa a l'Església va restablir totes les seues institucions i privilegis sense donar cabuda a la més lleugera innovació. Es tractava d'una simple i rotunda reconstitució del sistema antic, feta sota l'aliança entre el tron i l'altar, que va quedar ben enfortida pel restabliment de l'orde jesuïta (Revuelta 2008: vol. I 13-14). 
L'Institut ignasià va ser utilitzat com una peça del sistema absolutista, i els liberals, enemics del rei absolut, es veien abocats a ser-ho també de la Companyia, en la qual van veure reflectit el poder arbitrari de Ferran VII. I és que la restauració de l'orde de la mà d'un govern absolutista, va donar a la imatge dels jesuïtes un aire conservador $\mathrm{i}$ antiliberal.

Els ancians jesuïtes, desitjosos de tornar a la seua pàtria després d'un exili de quaranta-vuit anys, van acceptar agraïts l'honrosa restauració que els concedia el rei. Eren religiosos. No eren polítics ni venien a fer política -assegura Manuel Revuelta. Només venien a treballar i a ensenyar. I hi insisteix, tot afirmant, que els jesuïtes van tenir la desgràcia de renàixer en una Espanya dividida, sota el jou d'un partit, i ser vistos, sense pretendre-ho, com a representants de l'absolutisme (Revuelta 2004: 293-294). En canvi, Enrique Giménez diu que alguns jesuïtes exiliats - entre ells Lorenzo Hervás o Francesc Gustà- sí que havien contribuït, amb les seues actituds i escrits, a ser considerats aliats del monarca absolut i dels sectors més hostils a les innovacions, lligats a un passat anterior al de les Llums (Giménez 2007: 136). De fet, i amb motiu de la desfeta dels liberals del Trienni (18201823), el 7 de gener del 1824, el prepòsit general Luigi Fortis, ben agraït al rei hispànic pel nou restabliment de l'orde ignasià, escriví a Ferran VII exaltant la tornada a l'absolutisme i li va demanar protecció i ajuda en les tasques evangelitzadores i educatives dels jesuïtes. En la missiva assegurava al monarca que la Companyia estava «postrada a los pies del Trono Augusto de Vuestra Majestad». I que tot ho «dedicará y consagrará a la voluntad y obsequio de Vuestra Majestad, y a la utilidad de los Pueblos sujetos a la Corona de España» ${ }^{1}$. Aquesta submissió o aliança de l'Institut ignasià amb el poder reial de Ferran VII esdevindrà un estigma, una marca indeleble, que acompanyarà els jesuites en tot el segle XIX.

Després d'una missiva del papa Pius VII, datada el 15 de desembre del 1814, en la qual demanava al rei hispànic el restabliment de l'orde jesuïta en el seus dominis ${ }^{2}$, i després de molts memorials i cartes que havia rebut el monarca en què se sol licitava que els regulars de la Companyia tornaren als territoris hispànics, el 29 de maig del 1815, Ferran VII, nét de Carles III, restablia la Companyia de Jesús, i els antics jesuites serien admesos en els dominis de la corona espanyola -aquest monarca havia considerat falses les imputacions criminals que es van fer contra els religiosos. Es tractava d'un restabliment parcial en els pobles i ciutats que ho havien demanat. El decret diu així:

[...] he venido en mandar que se restablezca la religión de los Jesuitas por ahora en todas las Ciudades y Pueblos que los han Pedido, sin embargo de lo dispuesto en la expresada Real Pragmática Sanción de dos de Abril de mil setecientos sesenta y siete, y de quantas leyes y Reales órdenes se han expedido con posterioridad para su cumplimiento, que derogo, revoco y anulo en quanto sea necesario para que tenga pronto y cabal cumplimiento el

1 Archivo Histórico Nacional (d'ara endavant AHN), Estado, lligal, 3518. Document facilitat pel professor Enrique Giménez López.

2 Biblioteca Històrica de la Universitat de València (d'ara endavant BHUV), Ms. 0173 (14) Carta de Pio VII a Fernando VII congratulándose de que fuese bien acogida la resolución de restablecer la Compañia de Jesús, puesta en execución por la Constitución Apostólica de 7 de agosto de 1814 [...]. València: Francisco Brusola, 1814.

SCRIPTA, Revista internacional de literatura i cultura medieval i moderna, núm. 11/juny 2018/pp. 74-85

ISSN: 2340 - 4841 doi:10.7203/SCRIPTA.11.12585 
restablecimiento de los Colegios, Hospicios, Casas Profesas y Noviciados, Residencias y Misiones establecidas en las referidas Ciudades y Pueblos $[\ldots]^{3}$.

Amb aquestes paraules, el rei Ferran VII acceptava en els seus dominis la Companyia restaurada i li'n restituïa els béns. La pragmàtica de Carles III havia quedat derogada i s'ordenava a les autoritats que admeteren els jesuïtes en les antigues cases i col legis que estaven sense destinació. L'1 de juliol del 1815 Pius VII es va presentar a l'església del Gesù per notificar als superiors jesuïtes la restitució de l'Institut ignasià a l'Espanya dels Borbó (Fernández Arrillaga 2004: 53). Els jesuïtes exiliats es veien alliberats de quaranta-vuit anys de desgràcies.

El 3 de maig del 1816, després de rebre la consulta del Consell Reial, Ferran VII decretà el restabliment total de la Companyia, és a dir, «extensivo, general y sin limitacion á todos los demas de mis Dominios, asi de España como de las Indias, é Islas adyacentes en que se hallaba establecida dicha Religion al tiempo de su extrañamiento» ${ }^{4}$. Els regulars ignasians tenien protecció oficial, però al mateix temps, i com assenyala Revuelta González, aquesta protecció els imposava limitacions. La Companyia de Jesús només podria restablir-se en les cases antigues que li eren retornades, i amb les rendes velles que quedaven disponibles, però que havien minvat considerablement. Açò explica la precarietat de les restauracions: hi havia poques cases disponibles i les rendes eren insuficients (Revuelta 2013: 168).

Bisbes i ajuntaments reclamaven la seua presència, però sovint els posseïdors dels antics edificis de la Companyia s'hi oposaven i els jesuïtes pogueren recuperar-ne molt pocs. Les primeres cases que van prendre possessió els ja ancians homes de vida consagrada foren les de Manresa: el col legi i la residència de la Santa Cova, tan unida a les experiències espirituals de sant Ignasi. Entre els jesuïtes que arribaren a aquesta ciutat catalana, el 18 de juny del 1816, hi havia dos valencians, el P. Francesc Juan i Sevilla, natural d'Alacant, i el P. Francesc Català i Fenollar, de la vila de Planes (Comtat). Aquests, acompanyats pel salamanquí Juan Tronco, qui havia estat nomenat superior del col legi, van ser rebuts «á las puertas de la iglesia, salieron el cabildo y clero con aparato solemne y coro de música, y acompañaron á los Padres hasta el presbiterio, estando muy bien adornado el altar y llena la Seo de personas de todos los estados [...]. À los 25 de Junio con semejante aparato fueron instalados los jesuitas en sus antiguas posesiones. De la santa Cueva ofreció las llaves sobre azafate de plata D. Manuel Solá [...]» (Nonell 1893: vol. III 346-349).

No tots els ignasians pogueren tornar a terres hispàniques: uns perquè els ho impedia l'edat o la salut, i d'altres perquè optaren per quedar-se definitivament en les comunitats italianes. Els que se'n tornaren, van fer el viatge en grups i en moments diferents, i desembarcaren a Barcelona, a Alacant, al Grau de València i als Alfacs. Però la majoria -parlem de milers de bandejats- trobaren la mort en llur exili i van rebre sepultura a terres llunyanes. Van ser molts els cossos de religiosos i exreligiosos

3 Arxiu del Regne de València (d'ara endavant ARV), Secció Clergat, lligall 166-67, caixa 47, expedient 3.

4 ARV, Secció Clergat, lligall 166-67, caixa 47, expedient 3.

SCRIPTA, Revista internacional de literatura i cultura medieval i moderna, núm. 11/juny 2018/pp. 74-85

ISSN: 2340 - 4841 doi:10.7203/SCRIPTA.11.12585 
valencians que foren soterrats davall les lloses de les esglésies i en cementeris de Ferrara, Bolonya, Gènova, Venècia i Roma. Per la documentació consultada, tot i que siga una xifra aproximativa, podem dir que només hi hagué dotze ignasians, pertanyents als antics col legis jesuïtes valencians, que van ser expulsats el 1767 i moriren en el seu país d'origen. No podem oblidar, per la seua importància, el sacerdot llutxentí Vicent Soler i Ribelles, de la província del Paraguai, rector del restituït Col legi de Sant Pau, que morí a València el 14 d'octubre del 1828. Com tampoc no podem passar per alt el jesuïta valencià, del col legi de Calataiud, Vicent Peris i Carbonell, que fou soterrat a València, el 1821, després d'haver estat rector del Col legi de Sant Pau.

La Companyia restablida quedaria configurada en una sola demarcació administrativa: la província d'Espanya, i el seu primer provincial, amb títol de comissari general, seria el P. Manuel Zúñiga (Revuelta 2013: 235-240). Era una singular província formada per un grapat d'ancians -127 religiosos l'any 1815-, que feia quaranta-vuit anys que havien patit el desterrament decretat per Carles III. Tanmateix, el moment i la forma en què els jesuites van ser restaurats per Ferran VII durant el sexenni absolutista, es convertirà per a ells en un odiós estigma quan els liberals assumisquen el poder, ja que la Companyia serà el seu blanc (Revuelta 2008). Aquests, com ja hem dit, trobaran motivacions contra els jesuïtes, com el fet d'haver estat restablits per un rei absolut. De res van valdre les manifestacions proliberals que des de Sicília havien pronunciat alguns regulars de la Companyia durant les Corts de Cadis. Els nous governants s'estimaran més assumir els mites antijesuítics del temps de Carles III, i presentaran els ignasians com uns individus terribles, amb tants vicis que els havien fet mereixedors de l'expulsió del 1767, amb la qual cosa crearan un precedent per a la consecució de les supressions posteriors.

\section{E1 retorn dels jesuïtes a València}

El 16 de setembre del 1814, la Gazeta de la ciudad de Valencia donà la notícia de la restitució de la Companyia de Jesús, pel papa Pius VII, «en todo el orbe católico» ${ }^{5}$. València va ser de les primeres ciutats a demanar al rei Ferran VII el restabliment de l'orde jesuïta. Fou el 7 d'octubre del mateix any quan una representació de l'Ajuntament acudí al monarca per exposar-li la necessitat que tenien els joves valencians d'una «educación conveniente» (Frías 1923-1944: vol. I 232). El 31 de gener del 1815, el síndic personer, Pasqual-Antoni Ferrando i Gil, renovà la petició del consistori i manifestà al rei «los deseos de este fidelísimo pueblo, de que vuelvan los Jesuitas al mismo á exercer las funciones de su instituto» ${ }^{6}$. Amb motiu de l'expedició del reial decret, de 29 de maig del 1815, pel qual quedava restablit l'Institut de la Companyia, el síndic Ferrando tornà a dirigir-se al rei Ferran VII, el 24 de juny, per demanar-li que els jesuïtes prengueren possessió del Seminari de Nobles i

5 BHUV, Ms. 0519 (9) Gazeta de la Ciudad de Valencia de 16 de setembre del 1814.

6 BHUV, Diar. Antig. Diario de Valencia de l’1 de març del 1815.

SCRIP'TA, Revista internacional de literatura $i$ cultura medieval i moderna, núm. 11/juny 2018/pp. 74-85

ISSN: 2340 - 4841 doi:10.7203/SCRIPTA.11.12585 
de la Casa Professa «como en lo antiguo la tuvieron» ${ }^{7}$. Perquè València, segons afirmava, «desea ardientemente la pronta venida de los Jesuitas» ${ }^{8}$.

L'Ajuntament de València i un grup de veïns van contribuir a sufragar les despeses del viatge dels jesuïtes des dels estats italians fins a València. Francesc Xavier Borrull i Vilanova ${ }^{9}$, per exemple, oïdor que era de la Reial Audiència, el 8 d'agost del 1815 féu una aportació, per subscripció voluntària, de 500 rals de billó per a «atender á los gastos del regreso á España de los P.P. de la Compañia de Jesus» ${ }^{10}$. El 17 d'agost el consistori valencià informava a Tomás Moyano, secretari d'Estat i del Despatx de Gràcia i Justícia, que tenien arreplegats 12.000 rals de billó «a fin que se verifique su navegación [la dels regulars] a los puertos de España» ${ }^{11}$. Quan els primers jesuïtes van desembarcar al Grau de València el 5 de desembre del 1815 -eren 13 homes-, tant l'arquebisbe Arias-Teixeiro com els amics de la Companyia els van ajudar a trobar-hi allotjament. En canvi, el regent de l'Audiència i la Universitat van rebre els religiosos amb reticències (Frías 1923-1944: 237-238).

Remeses a la Real Junta de Restablecimiento de Jesuitas ${ }^{12}$ les representacions que havien fet al monarca l'Ajuntament de València i el síndic personer en què sol licitaven el restabliment dels jesuïtes a la ciutat, l'esmentada junta demanà informes a l'arquebisbe i al consistori sobre l'estat dels edificis jesuítics i de les rendes ${ }^{13}$. Havent sigut estudiada la documentació presentada, amb els corresponents inventaris, el 27 d'abril del 1816, el fiscal del Consell Reial va fer la necessària consulta al rei Ferran VII, i aquest, el 27 de maig del mateix any, ordenà que «se restituya y devuelva á los PP. de la Compañía de Jesús el Seminario de Nobles de esa ciudad, poniendo á su cargo, como lo tenian en el año 1767, el gobierno, dirección, y enseñanzas actualmente establecidas en él» ${ }^{14} \mathrm{i}$ «se restableciese la Casa Professa de esta Capital en clase y concepto de colegio conforme al Instituto de la Compañía» ${ }^{15}$. Amb aquesta finalitat, el corregidor i l'Ajuntament havien constituït una comissió

7 ARV, Secció Clergat, lligall 166-67, caixa 47, llibre de tapes negres (s.p.).

8 BHUV, Diar. Antig. Diario de Valencia de 20 de juny del 1816.

9 Erudit, jurista i polític. Fou diputat a Corts de Cadis el 1810.

10 BHUV, Ms. 0173 (17) Recibo firmado por D. Pedro Luis Traver a favor de Don Francisco Javier Borrull, por la subscripción voluntaria para atender a los gastos del regreso a España de los PP. de la Compañía de Jesús.

11 Arxiu Històric Municipal de València (d'ara endavant AHMV), D 221 Actes 1815, pp. 377.

12 Organisme estatal, creat el 19 d'octubre del 1815, que s'ocuparia de forma exclusiva de dur a terme totes les diligències que foren necessàries per a la restauració de la Companyia en els territoris hispànics.

13 ARV, Secció Clergat, lligall 166-67, caixa 47, llibre de tapes negres (s.p.).

14 BHUV, Diar. Antig. Diario de Valencia de 17 de juny del 1816. Sobre aquesta qüestió també podeu consultar: ARV, Secció Clergat, lligall 166-67, caixa 47, expedient 3 i llibre de tapes negres (s.p.).

15 BHUV, Ms. 0173 (23) Solemne acto, por el qual el M. I. Corregidory Ayuntamiento de la Ciudad de Valencia otorgó, en 18 de Julio de 1816, a los PP. de la Compañia de Jesús la escritura de restablecimiento en su primitivo domicilio titulado La Casa Profesa, Impremta

SCRIPTA, Revista internacional de literatura i cultura medieval $i$ moderna, núm. 11/juny 2018/pp. 74-85

ISSN: 2340 - 4841 doi:10.7203/SCRIPTA.11.12585 
particular amb dos regidors i els síndics procurador general i el personer «para que con el mayor celo y exactitud realizasen quanto se les prevenia» ${ }^{16}$. El dia 6 de juny, el consistori valencià agraïa a la Real Junta de Restablecimiento de Jesuitas les gestions realitzades perquè tornaren els regulars de la Companyia a la capital ${ }^{17}$.

Com veurem tot seguit, va ser el 18 de juliol del 1816 quan el P. Vicent Soler Ribelles ${ }^{18}$ prenia possessió formal de la Casa Professa, ara convertida en col legi (adoptà l'antiga denominació de Sant Pau) i dotat «con los bienes y efectos no enagenados pertenecientes al ramo de temporalidades de esta Ciudad y Noviciado de Torrente» ${ }^{19}$. Però l'1 de juliol del mateix any, els jesuites ja havien ocupat, també, el Seminari de Nobles de Sant Ignasi ${ }^{20}$, davant la presència del regent de l'Audiència i sense aparat fastuós (Frías 1923-1944: 234).

D'aquesta manera, a València havien quedat restaurades dues institucions jesuítiques dedicades a l'ensenyament: el Col legi de Sant Pau i el Seminari de Nobles, però no en edificis contigus com abans, sinó separats. El de Sant Pau, com hem vist, fou traslladat a l'antiga Casa Professa, «con las cátedras de Teología y las de Gramática, Retórica y Lengua Griega», i el seu rector va ser el P. Vicent Soler; mentre que el Seminari de Nobles, «con sus enseñanzas, rentas y edificios», va romandre en el seu antic edifici ampliat, i seria el seu rector el jesuïta i escriptor ontinyentí Antoni Conca i Alcaraz. Es van formar així dues institucions acadèmiques separades, en llocs diferents i dirigides per comunitats diferents (Revuelta 2013: 282). El Seminari de Nobles de Sant Ignasi havia estat tornat «con toda la extension en que se halla», i el Col legi de Sant Pau «con las mismas Cathedras y Magisterios que tenian los PP. de la Compañia en el año $1767 »^{21}$. A la darreria del 1816, el Col legi de Sant Pau, sota la direcció del jesuïta valencià Vicent Peris i Carbonell²2,

de Benito Monfort, València, 1773, pp. 8.

16 Ibidem.

17 AHMV, D 223 Actes 1816, pp. 342-343 v. L'1 de juny del 1816, l'Ajuntament s'havia assabentat dels bons oficis de Manuel Abad, secretari de la Real Junta de Restablecimiento de Jesuitas, «de haberle servido mandar el Rey [el 27 de maig] que restituya y devuelva a los jesuitas el Seminario de Nobles». Vegeu: AHMV, D 223 Actes 1816, pp. $229 v$.

18 Aquest religiós va nàixer a Llutxent (Vall d'Albaida) el 27 d'abril del 1749. Entrà a la Companyia de Jesús al Paraguai el 12 de juny del 1766 i va fer la professió solemne el 25 de maig del 1808. L'expulsió del 1767 el va sorprendre a Tarragona, amb altres novicis de la província del Paraguai. Morí a València el 14 d'octubre del 1828.

19 BHUV, Ms. 0173 (23) Solemne acto..., op. cit., pàg. 8 i ARV, Secció Clergat, lligall 166-67, caixa 47, expedient 3 i llibre de tapes negres (s.p.).

20 BHUV, Ms. 0519 (20) Seminario de Nobles.

21 Archivo Histórico de Loyola (d’ara endavant AHL), Colegios 15/6: "Carta de 29 de julio de 1816 del Ayuntamiento de Gandía suplicando se acelere el proceso de restablecimiento del Colegio de Gandía).

22 L'any de l'expulsió era escolar a Calataiud. Estigué exiliat a Gènova fins al 1814. Nasqué a Castelló de la Ribera el 8 d'agost del 1746 i morí a València el 27 d'octubre del 1821. Era fill de Vicent Peris, natural de Castelló de Xàtiva (ara 
comptava amb sis jesuïtes -entre els destinats hi havia l'historiador i humanista Joan Francesc Masdéu- i cinc el Seminari de Nobles.

El 18 de juliol del 1816 s'organitzà a la ciutat de València una gran festa quan els jesuïtes repatriats van prendre possessió de l'església i de l'antiga Casa Professa -amb l'expulsió dels regulars de la Companyia, aquesta havia estat convertida en seminari sacerdotal, escoles i arxiu del regne de València. Totes les autoritats de la ciutat hi estaven presents: Ajuntament, Reial Audiència, Capitania General, Universitat, Inquisició, capítol eclesiàstic, rectors i superiors religiosos, nobles, etc. Amb un acompanyament sumptuós, amb músics uniformats i muntats en cavalls engalanats per a l'ocasió, els pares van ser conduits en bells i elegants cotxes fins a l'església, on els esperaven les esmentades il lustres personalitats. Quan el religiós seguici va arribar a la plaça de la Companyia, la tropa armada va haver d'obrir-los pas perquè els jesuïtes pogueren accedir al temple entre els víctors de la multitud ${ }^{23}$.

El 17 de setembre, en la missa d'acció de gràcies pel restabliment de la Companyia, celebrada pel canonge Antoni Roca i Pertusa a l'església jesuïta de València, el P. Josep Giner, religiós jerònim i prior del Reial Monestir de Sant Miquel dels Reis, va dir en el sermó que ha estat «en esta época, Señores, precisamente, en esta época se levanta del polvo, renace mas hermosa, llama la atencion, recibe las bendiciones, triunfa la Compañía de Jesús, esa Sociedad Religiosa, tantos años perseguida, oprimida, atribulada! [...]. Así pues, ó amada Valencia! acaso la primera en los deseos, eres de las primeras en la consolación. Ya tierna tiendes tus brazos, y caricias á los que tantos años has llorado: ya los tienes en tu seno, y ellos juran corresponder á tus cariños» (Giner 1816: 4-5). L'endemà, en la missa en sufragi per les ànimes dels jesuïtes difunts, celebrada pel canonge Joaquim Piquer al mateix temple jesuític, el dominic valencià Marià Bonet ${ }^{24}$, encarregat de predicar, amb joia deia que «Valencia, esta muestra amada y religiosa Patria, entre demostraciones del mayor aprecio, y de un placer extraordinario, acaba de colocar en sus casas, dentro los muros de la Ciudad, esos restos preciosos del Instituto del Grande Loyola, que había pedido con tanta anticipacion, esperado con tantas ansias, y abrazado por último con tanta cordialidad» (Bonet 1816: 36).

En els segles XIX i XX la Companyia de Jesús va patir supressions i nous exilis, depenent del govern i de fortes tensions polítiques. Durant el Trienni Liberal (1820-1823), en el període entre 1835 i 1852, després de la Revolució de Setembre del 1868 (La Gloriosa) i en la Segona República, l'orde ignasià fou dissolt, el 1932, pel seu quart vot d'obediència al papa, autoritat diferent a la de

Castelló de la Ribera), advocat dels Reials Consells, relator de l'Audiència de València i Alcalde Major. El religiós Vicent Peris va ser nomenat rector del Col legi de Sant Pau de València el 20 d'octubre del 1816.

23 BHUV, Ms. 0173 (23) Solemne acto, por el qual el M. I. Corregidory Ayuntamiento de la Ciudad de Valencia otorgó, en 18 de Julio de 1816, a los PP. de la Compañia de Jesús la escritura de restablecimiento en su primitivo domicilio titulado La Casa Profesa, Impremta de D. Benito Monfort, 1816, València, pp. 9-14.

24 Ministre qualificador i revisor de llibres del Sant Ofici. Inquisidor ordinari pel bisbat d'Albarrasí i regent d'estudis del convent dels frares predicadors de València.

SCRIPTA, Revista internacional de literatura i cultura medieval $i$ moderna, núm. 11/juny 2018/pp. 74-85

ISSN: 2340 - 4841 doi:10.7203/SCRIPTA.11.12585 
l'Estat. Un decret signat pel general Francisco Franco, el 3 de maig del 1938, restablia l'Institut de la Companyia en l'anomenada zona nacional (controlada pels insurrectes), que s'estenia a tot l'Estat espanyol en finalitzar la Guerra Civil ${ }^{25}$.

Si la Companyia restaurada era de tarannà conservador, amb uns religiosos més inclinats a buscar solucions en la tradició que no pas en el risc de noves experiències, a partir de la Congregació General XXXI els jesuïtes tingueren un altre comportament, un nou estil. Van venir anys amb demandes de canvis i de gestació de nous projectes, que produïren reajustaments quasi vertiginosos en l'orde. El prepòsit general Pedro Arrupe va saber introduir en l'Institut ignasià l'esperit del Concili Vaticà II, que obrí l'Església a la modernitat i inaugurà la primera primavera de la institució eclesial. Naixia la Companyia de Jesús renovada.

25 El règim de Franco es trobà amb alguns opositors dins la Companyia de Jesús, principalment entre els jesuïtes bascos i catalans, d'idees nacionalistes. 


\section{Bibliografia}

Bonet, M. (1816) Sermón fúnebre que en el aniversario solemne celebrado por las almas de los RR. Padres y Religiosos difuntos de la Compañia de Jesús, València, Impremta de D. Benito Monfort.

Fernández Arrillaga, I. (2014) «La Restauración de la Compañía de Jesús en primera persona: el P. Manuel Luengo», Manresa. Revista de Espiritualidad ignaciana, 86, pp. 73-82.

—. (2004) El destierro de los jesuitas castellanos (1767-1815), Valladolid, Junta de Castilla y León.

Frías, L. (1923-1944) Historia de la compañia de Jesús en su asistencia moderna de España, II vol., Madrid, Administración de Razón y Fe.

Giménez López, E. (2007) «Jesuitas», dins Canal, J. (ed.), Exilios. Los éxodos políticos en la bistoria de España. Siglos XV-XX, Madrid, Sílex, pp. 113-136.

Giner, J. (1816) Sermón, que en la fiesta celebrada en acción de gracias por el restablecimiento de los PP. de la Compañia de Jesús, València, Impremta de D. Benito Monfort.

Gutiérrez de la Huerta, F. (1845) Dictamen del fiscal don Francisco Gutiérrez de la Huerta presentado y leído en el Consejo de Castilla (1815) sobre el restablecimiento de los jesuitas, Madrid, Imprenta de Don Agustín Espinosa y compañía.

Monjo i Dalmau, F. J. (2016) Expulsió, exili i retorn dels jesuïtes del País Valencià (1767-1816), Alacant, Universitat d'Alacant, [Tesi doctoral].

Nonell, J. (1893) El V. P. José Pignatelli y la Compañia de Jesús en su extinción y restablecimiento, III vol., Manresa, Ed. San José.

O’Malley, J. W. (2017) Los jesuitas y los papas. Cinco siglos de historia, Bilbao, Mensajero.

Revuelta González, M. (2013) El restablecimiento de la Compañia de Jesús. Celebración del bicentenario, Bilbao, Mensajero.

-.(2008) La Compañía de Jesús en la España contemporánea, III vol., Madrid, Universidad Pontificia Comillas.

-.(2004) «La Compañía de Jesús restaurada (1815-1965)», dins Egido, T. (coord.) Los jesuitas en España y en el mundo hispánico, Madrid, Marcial Pons, pp. 281-395. 